\title{
Charting in Switzerland: Developments and Perspectives
}

\author{
Pascal Mösli
}

Pastoral documentation is developing rapidly in Switzerland: it is now an established part of the palliative complex treatment required of hospitals by guidelines drawn up by pastoral teams in the interprofessional context of mainly large hospitals and endorsed by pastoral expert committees. Despite this development, it remains controversial whether pastoral documentation is appropriate. In order to understand how pastoral care professionals throughout Switzerland think about documentation, a survey of German-speaking pastoral care professionals was conducted in Spring 2019.

This article gives an overview of the most important developments in pastoral documentation, summarizes debate surrounding it, and presents the results of the survey among chaplains. The documentation practice of three hospitals is then presented in order to provide a deeper insight into the concrete practice of documentation before the final section discusses some of the questions and future challenges pastoral documentation in Switzerland faces.

\section{Introduction ${ }^{1}$}

Healthcare chaplaincy in Switzerland operates in a very diverse regulatory landscape. Depending on the canton, there are different legal and ecclesiastical framework conditions. In many cantons, hospital chaplains are church employees; in

\footnotetext{
${ }^{1}$ I would like to thank Simon Peng-Keller, who supports me a great deal in my research work and with the writing of this article, as well as my colleagues Saara Folini-Kaipainen, Claudia Graf, Livia Wey-Meier, and David Neuhold from the National Science Foundation research project Documentation, with whom I am in a creative, exciting dialogue. They have all read the article critically and given me a lot of helpful feedback.
}

P. Mösli (ه)

University of Zurich, Zurich, Switzerland and Reformed Church of Bern

e-mail: contact@pascalmoesli.ch 
others, they are employees of the relevant institution; and in some cantons, the state contributes funds. In contrast, the professional prerequisites for pastoral work in hospitals are largely uniform: a university degree in theology, additional pastoral psychological training, and a mission from one of the three churches that are officially recognized in most Swiss cantons. These churches are the Roman Catholic Church, the Reformed Church, and the Christian Catholic Church. (The Jewish community is also recognized in many cantons.) $60.9 \%$ of the Swiss population are a member of one of these three national churches $(36.5 \%$ Roman Catholic and 24.4\% Reformed, with around 15,000 members of the Christian Catholic Church), $5.8 \%$ belong to other Christian communities, $5.2 \%$ are Muslim, $1.7 \%$ belong to other religious communities, and $25 \%$ are nondenominational. ${ }^{2}$

There are two national umbrella organizations for German-speaking healthcare chaplaincy in Switzerland: the Reformed and the Roman Catholic pastoral care associations. In some cantons, but by no means all, there are professional standards for pastoral care in hospitals, but there are none at the national level.

Until 5 years ago, most chaplains in Switzerland did not contribute to interprofessional charts. Most chaplains would not have considered doing so for a moment, and those that did would most likely have rejected the idea for reasons of confidentiality. On the other hand, many chaplains have been documenting their work for their own purposes for a long time. For example, they may have recorded which topics were discussed in a conversation and use the documentation as an aidememoire, to help maintain the relationship with the patient and for reflection.

Another field in which a form of documentation is used is training: For many years, excerpts of conversations have been used in Clinical Pastoral Training (CPT) courses for educational purposes. The purpose of the documentation here is therefore to help one reflect on one's own professional actions. Each week, the participants in a course bring with them minutes from a meeting in their field of practice. There is also a manual for writing the minutes of a discussion. The verbatim reports are analyzed and discussed in the training group, sometimes used as a template for a case discussion and then returned to the authors. This is an established and effective learning method in the context of pastoral training.

Only in a few hospitals, usually larger ones, have chaplains been charting in an interprofessional context, or within the pastoral care team, for more than a few years. Often this has taken place where pastoral care is administered on behalf of the institution or the state and is also financed by the latter. I will come back to this point.

\footnotetext{
${ }^{2}$ Figures for the year 2017, Federal Statistical Office: https://www.bfs.admin.ch/bfs/de/home/ statistiken/bevoelkerung/sprachen-religionen/religionen.html, accessed 20 July 2019.
} 


\section{The Current Development}

The situation in Switzerland has been in a state of flux for about 5 years now. This change has to do with the digitalization of the healthcare system and with the implementation of electronic documentation methods. The electronic patient file (EPD) is a collection of personal documents with information about the health of the patient. This information can be accessed via an Internet connection. Patients grant access to caregivers and determine who can view which documents. The law and implementing provisions on electronic patient files came into force on 15 April 2017. Since then, hospitals have had 3 years to introduce the electronic patient file, while nursing homes and birth centers have had 5 years. This rapid development in the healthcare system raises the question of whether pastoral care should feature in interprofessional, electronic documentation.

But the mentioned change also has to do with developments in professional pastoral care itself - especially in the fields of emergency, palliative and spiritual care, and relating therefore to the concerns of interprofessional cooperation. These developments are described below.

\subsection{Emergency Care}

An important context in which documentation systems have developed is emergency pastoral care. On the one hand, the documentation serves as an information basis for intraprofessional work to enable other chaplains in the team to continue the work of companionship. On the other hand, documentation can demonstrate to the institution the importance of this care provision and the corresponding staff resource requirements.

\subsection{Palliative Care}

The decisive step for the integration of chaplaincy as part of the palliative care teams was taken by the National Strategy for Palliative Care of the Federal Office of Public Health, ${ }^{3}$ which regards spiritual care as an integral part of palliative care (following WHO standards). Interprofessional cooperation including pastoral care thus became standard for palliative care. This development was further supported by the financial incentive system. Since 2011, palliative services in Switzerland have been billed within the framework of the CHOP (Swiss Operation Classification ${ }^{4}$ ) system.

\footnotetext{
${ }^{3}$ Bundesamt für Gesundheit (BAG).

${ }^{4}$ Version 2019: www.bfs.admin.ch/bfs/de/home/statistiken/kataloge-datenbanken/publikationen. assetdetail.5808569.html
} 
Pastoral caregivers and other psychosocial professional groups play an important role in fulfilling the two CHOP codes 93.8A.2 and 93.8A.3. These stipulate that the multidisciplinary treatment team, consisting of a doctor, nursing staff, and staff in at least two of the therapeutic areas (social work/pedagogy, psychology, psychotherapy, ergotherapy, speech therapy, nutritional counseling/therapy, pastoral care, art therapy), will work a total of at least 6 hours per treatment week. In many hospitals in Switzerland, specialists invoice their services electronically in a form specially created for this purpose, which automatically evaluates the criteria for the complex code. Support within the framework of palliative complex treatment is the only pastoral service in Switzerland which has direct financial consequences or which has an impact on a hospital's income. It belongs to the group of services that must be fulfilled in order to receive the financial contributions of the insurance companies and to guarantee the (re)certification of the palliative wards. The prerequisite for this, however, is the documentation of pastoral services, if only in respect of the duration of pastoral attendance. If the chaplain is not prepared to keep records, the ward will (have to) use other services, like the psychological service. Pastoral care thus runs the risk of dropping out of the treatment team.

\subsection{Spiritual Care}

In recent years, we have seen significant and quite diverse developments in spiritual care as an interprofessional task in Switzerland - in the field of palliative care and beyond. In this context, two documents have emerged that are very important for our topic.

First is the document of the "Spiritual Care Taskforce" of "palliative.ch", the Swiss Society for Palliative Care": "Spiritual Care in Palliative Care. Guidelines on Interprofessional Practice." This document contains the following statement on documentation: "Interprofessional Spiritual Care requires intensive communication, including medical documentation as an important tool. Requirements for the documentation of $\mathrm{R} / \mathrm{S}^{7}$ : (a) it is part of the documentation system accessible to all members of the treatment team; (b) all professional groups involved are requested to chart observations and agreements on R/S if they are relevant to the treatment and (c) the special and context-specific professional framework conditions regarding the possibility and limits of pastoral communication must be taken into account (keyword: pastoral secret)" (Spiritual Care 2018, 12f).

Second, in June 2019, the professional pastoral care group of palliative.ch published its guidelines "Pastoral Care as Specialized Spiritual Care in Palliative

\footnotetext{
${ }^{5}$ The Spiritual Care Taskforce supports interdisciplinary work toward a better understanding of Spiritual Care in Palliative Care. It is made up of experts from various professions.

${ }^{6}$ The guidelines ("Spiritual Care in Palliative Care. Leitlinien zur interprofessionellen Praxis") can be downloaded here: https://www.palliative.ch/de/fachbereich/task-forces/spiritual-care.

${ }^{7} \mathrm{R} / \mathrm{S}$ means religious/spiritual.
} 
Care".${ }^{8}$ Guideline 7 (access to information and documentation of care) broaches the issue of documentation: "As a member of the treatment team, the pastoral care specialists have access to information that will allow them to adapt their concept of spiritual-religious support. [...] The formal and/or informal exchange of information contributes to the strengthening of the team spirit and a positive culture within the treatment team. The information is recorded in the part of the electronic data record intended for pastoral care. In the electronic patient file spiritual/religious elements can be noted; the elements of the electronic patient file are available for all involved experts; the pastoral care specialist is in contact with the interprofessional team" (Leitlinien 2019, 14f).

\subsection{Conclusion}

The developments described above show that the topic of documentation within pastoral care has developed intensively in recent years and gained in importance. External factors, such as institutional requirements and the financial settlement of complex palliative services, have been crucial, but so also have developments within the profession of pastoral care itself. The insight that documentation could contribute to the professionalization of pastoral care was increasingly important. Alongside the initiatives of some pastoral care specialists, important roles were played by pastoral care units in large hospitals and professional associations, such as the Protestant and Roman Catholic National Pastoral Care Association and the Professional Pastoral Care Group of palliative.ch. The National Pastoral Care Associations have recognized the importance of the topic since 2013. They initiated the research project for documentation and organized the first conference on the topic. In order to better understand the importance of documentation for chaplains and their attitude toward it, a survey with the support of the Pastoral Care Associations was commissioned. This survey will be presented in the next two sections.

\section{A National Survey}

\subsection{Occasion}

It was remarkable that all discussions about documentation - be they conferences or collegial meetings - provided an opportunity to discuss fundamental topics of pastoral work and its profile. When confronted with the documentation topic, chaplains discussed the possibilities and limits of language; the connections between spiritual

\footnotetext{
${ }^{8}$ The guidelines ("Leitlinien. Seelsorge als spezialisierte Spiritual Care in Palliative Care") can be downloaded here: https://www.palliative.ch/de/fachbereich/fachgruppen/fachgruppe-seelsorge.
} 
and religious matters with physical, psychological, and social phenomena; the question of individuality; and so on. Also interesting was the high emotional intensity with which the documentation was discussed. The topic of documentation hardly ever leaves anyone cold. Obviously, the topic challenges pastoral professionals to take a stand.

But what exactly do chaplains working in institutions think about pastoral documentation? How do they assess documentation in the context of the development described above? Do they chart themselves? Would they be prepared to do so? - Or is documentation not an appropriate pastoral instrument, in their view? These and other questions were put to chaplains in order to better understand their selfconception and practice. The results of this survey are explained and discussed below.

\subsection{The Participants}

In March 2019 we sent the questionnaire to 142 Protestant and 134 Roman Catholic chaplains who are members of the Reformed and Roman Catholic Pastoral Associations. Most institutional chaplains in Switzerland are members of one of these two national associations. ${ }^{9}$ In total there were 276 people, 5 of whom were retired. Therefore, 271 people were relevant for the survey.

One hundred and forty eight chaplains completed the questionnaire, which corresponds to a response rate of $54 \%$. We can therefore say that the survey provides a good insight into the Swiss situation.

Among the participants, 77 were Protestant chaplains, 70 Roman-Catholic chaplains, and one chaplain belongs to another denomination (unknown to us). 104 of the participants work in a hospital, 21 in a psychiatric clinic, 37 in old-age institutions, and 20 in other contexts (Fig. 1).

An important factor for questions about charting is the appointing authority. The employment conditions of institutional pastoral workers in Switzerland are complex: some employers are churches; sometimes the state plays this role and sometimes the institution. Moreover, there are also mixed forms of employment.

Thirty one participants in our survey are employed by the institution they work in, 120 by the church, and 16 by the government. One person has a different employer (Fig. 2).

The different employment arrangements bring with them different expectations, with consequences for the perception and assessment of documentation:

- With regard to health service providers, pastoral care must make clear what it offers as its service, which quality standards it is committed to, how it secures these, and what framework conditions and resources it requires for this purpose.

\footnotetext{
${ }^{9}$ Efforts are underway to establish the number of institutional chaplains in Switzerland. However, no results are available yet.
} 


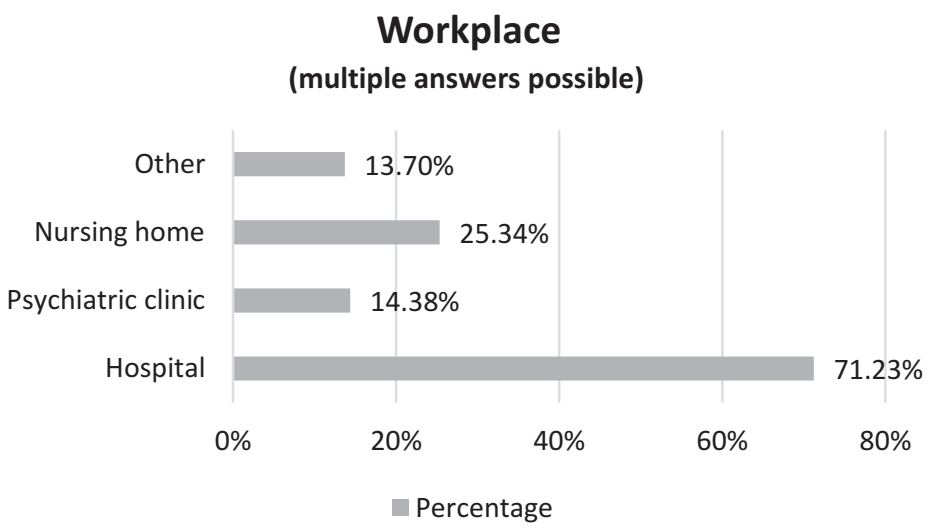

Fig. 1 Workplace

\section{Appointing authority}

(multiple answers possible)

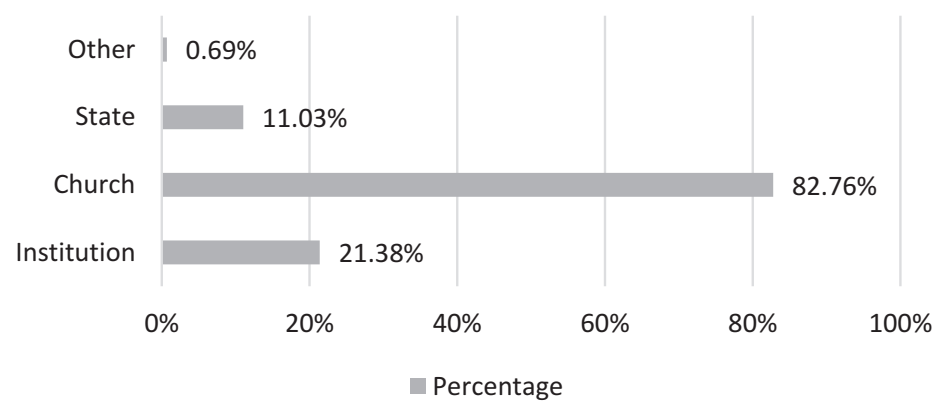

Fig. 2 Appointing authority

- With regard to the institutions of the health system, pastoral caregivers must show what specific contribution they make in interdisciplinary cooperation and how they network with other occupational groups.

- With regard to the state and social authorities, pastoral caregivers must show that they do not only care for church members but also for other members of the multicultural and multi-religious environment. They support people of all worldviews in a non-exhaustive way. They are thus oriented toward an open society that stands up for human rights and human dignity.

- With regard to the churches, pastoral caregivers must show how they justify their mission from within their religious tradition and how they fulfill it in a contemporary way. 
The employment arrangements of chaplains are an important framework condition for the questions of the necessity of interprofessional cooperation and of the depth and nature of the integration of pastoral care in the institution. Such arrangements therefore also have an influence on the treatment of professional and pastoral secrecy, which will be discussed later.

\section{The Results of the Survey}

\subsection{General Results}

An important result is simply the response rate: Documentation is a topic that many chaplains are occupied with or want to deal with. This finding is confirmed by the many responses from participants (more than $50 \%$ of those who took part in the survey), who told us that they were willing to participate in further discussion. ${ }^{10}$

It is also clear that the confessional background of chaplains does not influence response rate: Of the Protestant chaplains, 77 participated, and of the Roman Catholic chaplains, 70. In relation to the questionnaires sent, this corresponds to a rate of $55 \%$ of Reformed chaplains and $53 \%$ of Catholic chaplains.

It can also be assumed that the topic of documentation is more important in hospitals than in other institutions. $57 \%$ of the data were received on the institutional field of hospitals. This is perhaps a reflection of the interprofessional integration of pastoral care, which is tightest in hospitals.

\subsection{Charting: Yes or No?}

But to what extent do chaplains in Switzerland record institutional pastoral care in interprofessional documentation? All participants answered this question. 44 of the participants contribute to interprofessional documentation; 27 chart only in the context of complex treatment in the field of palliative care; 74 chaplains do not chart. In summary, $49 \%$ of all chaplains contribute to documentation in an interprofessional context (including palliative care); $51 \%$ do not chart at all. We will break down the number of those who currently do not chart further in connection with the question of who can imagine charting and who cannot (Fig. 3).

However, the fact that a chaplain does not currently chart in an interprofessional context does not necessarily mean that he or she does not want to chart now or in the future. There are several reasons why chaplains cannot chart interprofessionally or are not allowed to. The institution, as well as the commissioning church, may prohibit this, and there may be no possibility of making pastoral entries in the existing

${ }^{10}$ The field at the end of the survey was "contact permission." 


\section{Basic question about documentation (only one entry possible)}

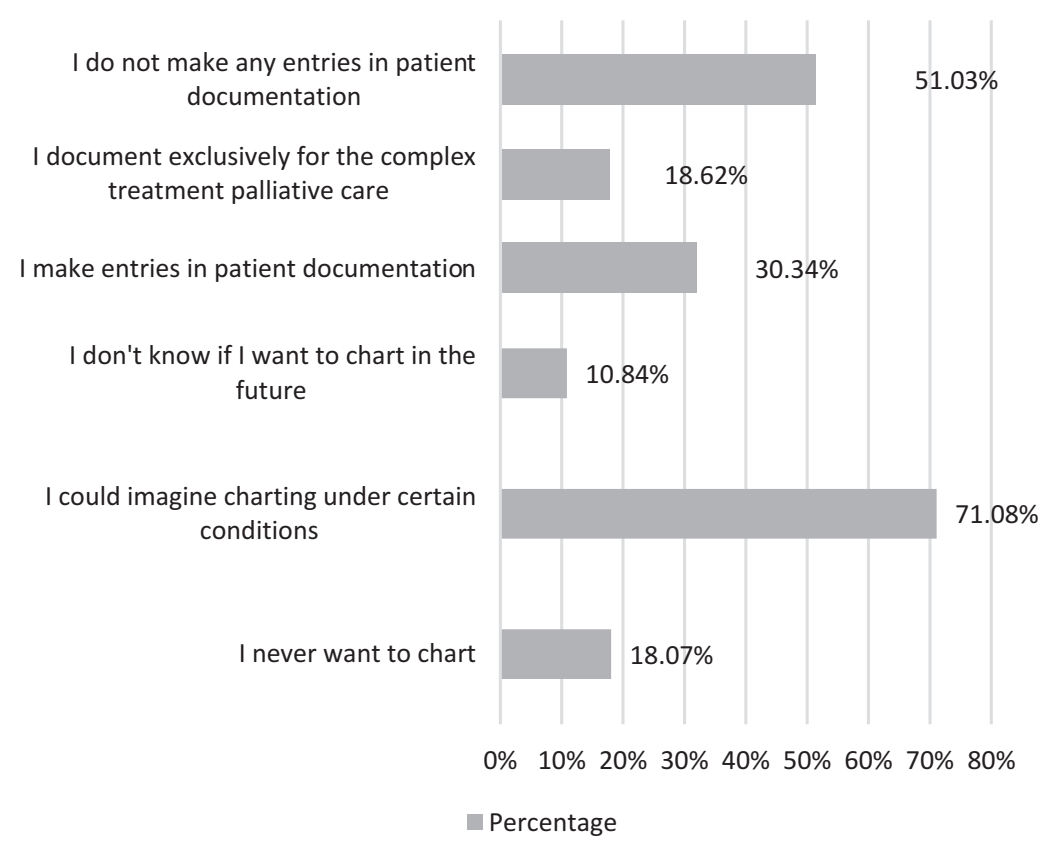

Fig. 3 Basic question about documentation

documentation. We therefore asked those who are not currently charting whether they would prefer not to chart under any circumstances or whether there are circumstances under which they would like to chart. Out of a total of 83 answers to this question, 15 people stated that they never wanted to chart and 9 people said that they do not know whether they want to chart under different circumstances. 59 people stated that they would chart under certain circumstances $-71 \%$ of respondents.

While the question above was about interprofessional documentation, we also asked chaplains whether they contribute to documentation for themselves (with nobody else having access) and whether they contribute to documentation for the members of the team (with access restricted to the members of the pastoral team). 109 respondents answered this question. 96 people chart for themselves and 39 for the members of the team. With this question, it was possible to agree to both answers. We therefore do not know whether there are chaplains who chart only for members of the team but do not keep additional records exclusively for themselves (Fig. 4).

However, we can see that $88 \%$ of all participants chart for themselves, while only $49 \%$ contribute to interprofessional documentation. We can conclude that documentation for one's own work is part of pastoral workers' common practice, while interprofessional documentation is on the rise. It would be exciting to investigate whether 


\section{For whom do you chart (multiple answers \\ possible)}

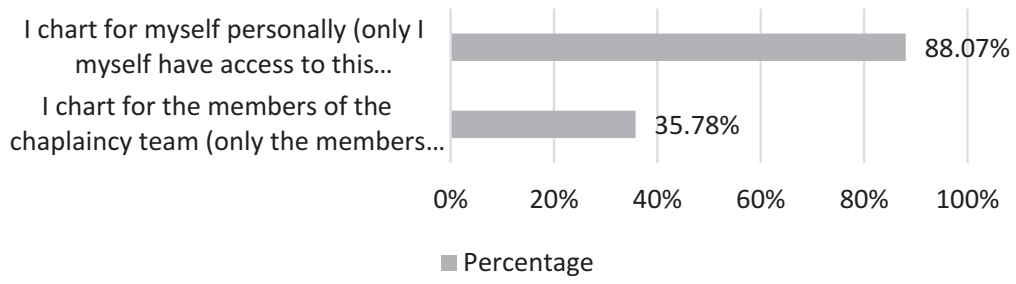

Fig. 4 For whom do you chart

personal documentation follows a conceptual basis or whether it is a rather accidental documentation of important experiences or insights, in order to be able to further inform the accompanying process.

\subsection{Reasons to Document}

We have already seen that employment arrangements, and the context of justification they create, are significant determinants of documentation practice. Pastoral workers were asked why they do or do not chart, and 132 responded (16 people skipped the question).

Most chaplains contribute to documentation on the instructions of their institution (65 people, $49 \%$ ), while almost as many chart for personal reasons (61 people, $46 \%) .39$ people (30\%) chart in accordance with a team decision, 22 people $(17 \%)$ in accordance with the decision of a superior, while 8 people $(6 \%)$ do so on the instruction of their church (Fig. 5).

Given the initial situation outlined above, the findings are not surprising. Healthcare institutions have an interest in somehow being able to measure the effects of professional interventions, and in the case of the palliative complex treatment already mentioned, such measurements have financial significance. Where pastoral care work is on behalf of the institution and is paid for by it, it is naturally perceived to be part of the work of the institution, which often leads to increased interprofessional cooperation. In the context of this, documentation can be an important instrument of communication.

The interprofessional integration of pastoral care has already been discussed several times. When asked to document their reasons for charting, 24 out of a total of 36 comments in the free text fields referred to interprofessional cooperation. This is regarded as an essential prerequisite for the practice of pastoral care. Interprofessional cooperation was also cited in most of the comments in the free text field about the circumstances under which chaplains might consider charting. 


\section{I am charting for the following reasons / I am not charting for the following reasons}

(multiple answers possible)

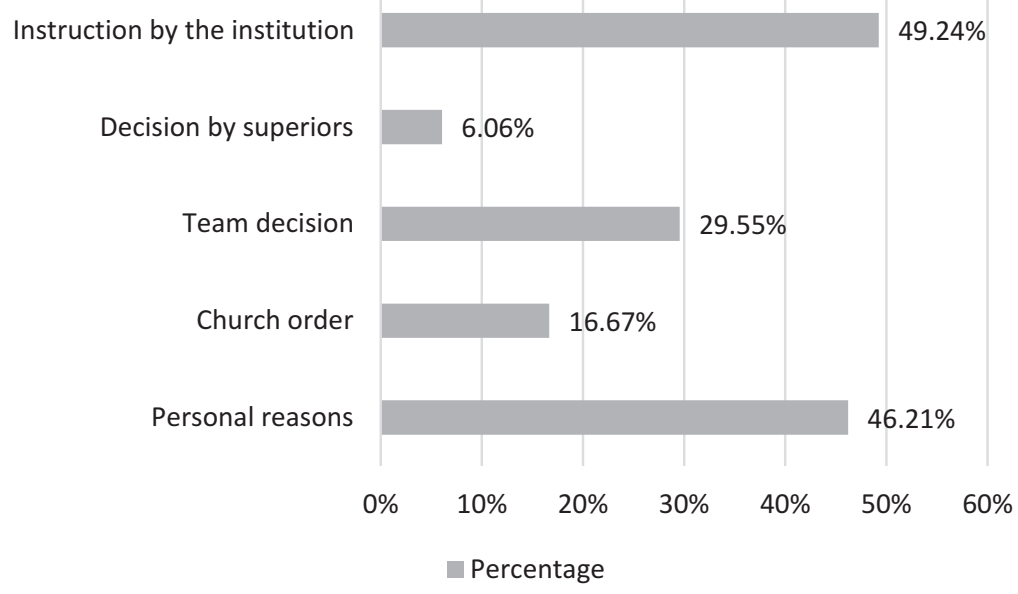

Fig. 5 Reasons for (not) charting

\subsection{Confidentiality}

Professional secrecy is a constraint on the exchange of information. Determining the nature and extent of the constraint pastoral secrecy imposes relationship is in itself a challenge for pastoral work, especially in the context of interdisciplinary cooperation. One response to this challenge is a handbook published in 2016 by the Federation of Swiss Protestant Churches on the subject (Famos et al. 2016). The various Reformed cantonal churches in Switzerland, as well as the Catholic dioceses, are familiar with different forms of the pastoral confidentiality. There are different views as to what, if anything, of the substance of an encounter it is permissible to pass on in interprofessional discourse and what scope there is for interprofessional cooperation and what practices are prohibited. The question of how pastoral secrecy relates to professional secrecy is also controversial.

The pastoral secret was not an explicit topic of the survey, but it did play a role in the respondents' answers. Chaplains who do not contribute to interprofessional documentation were able to explain their reasons in a free text field. 56 people took up this opportunity ( $42 \%$ of all entries). Of these 56 persons, 8 cited the pastoral confidentiality as a reason why they do not document ( 12 mentioned that they use other means of communication, 27 said that their institutional context does not allow them to document, 9 gave further reasons). It must be stressed that we did not 
explicitly ask about the importance of the pastoral secret, so the number of responses should be interpreted with caution. Taken together with the other results, one could perhaps give the following summary: the pastoral secret plays an important role in the whole discourse, but it is not principally a stop signal for the possibility of interprofessional documentation.

\subsection{The Practice of Documentation}

Finally, we asked the chaplains about their charting practices. The responses were as follows:

- I chart regularly: 40 replies.

- I chart if necessary: 36 replies.

- I chart according to specific guidelines: 28 replies.

- I chart not according to specific guidelines: 12 replies.

- I chart by hand: 17 replies.

- I chart electronically: 54 replies (Fig. 6).

What is noticeable is that only a few chaplains chart according to specific rules or guidelines. This reflects the earlier observation that documentation as a standardized instrument is still in its infancy.

\section{Information in case you chart interprofessionally \\ (multiple answers possible)}

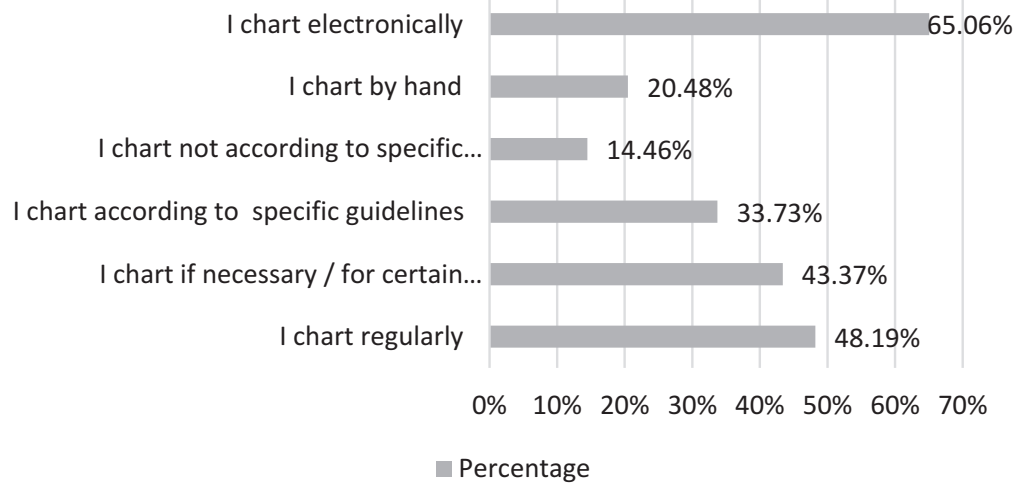

Fig. 6 Information in case of interprofessional charting 


\section{Three Examples of Charting Systems in Switzerland}

Now that the survey has provided a detailed picture of the attitudes and practices of chaplains in institutions in Switzerland, this section will outline a more concrete picture of existing documentation models in Switzerland. There is a wide variety of documentation practices in Switzerland. In some cases, documentation extends only to registration; in others, the involvement of pastoral care is registered without any further information; and in some cases, pastoral information is recorded to inform assessment-based treatment.

In his article "How do we measure quality in charting?" David Lichter (2015, 3ff.) described three forms of quality assurance in charting:

- Process measures focus on processes that lead to a certain outcome.

- Outcome measures focus on results.

- Performance measures relative to professional standards focus on the measurable standards agreed upon across the profession.

As shown above, professional standards for pastoral documentation have been developed in Switzerland in the context of specialized palliative care. These standards would be the basis for the form of quality assurance mentioned under (c). The consistent implementation of these standards, as well as the other forms of quality assurance mentioned by Lichter, is still a long way off in Switzerland. The standards express the ambitions of chaplains working in palliative care have for documentation, rather than requirements implemented in practice.

The following three examples come from pastoral care units in large hospitals in the cities of Zurich, Bern, and Lausanne. The documentation models in Zurich and Bern, like most Swiss models, have been developed as a pragmatic response to the need to deepen and consolidate interprofessional cooperation. The model in Lausanne is an exception to the Swiss norm, because, on the one hand, it has a pastoral-conceptual basis and can therefore be linked to the first two forms of quality assurance of process measures and outcome measures; and, on the other hand, it has been conceived as an instrument for interprofessional cooperation.

\subsection{Triemli Hospital in Zurich}

The "Stadtspital Triemli" is a central hospital in the city of Zurich with a supraregional catchment area. With 467 beds and around 3,000 employees, it provides around 400,000 people with comprehensive basic and emergency care. The pastoral care team consists of seven pastoral workers (three Reformed and four Catholic).

Pastoral care has gained access to the electronic documentation system in the hospital, but it has been a long road to this point. Only after several requests were the hospital's responsible persons prepared to set up a working group to deal with 
this issue. This working group was set up to determine what information from nursing documentation it is necessary and important for pastoral care workers to be able to access if they are to participate in the framework of interprofessional cooperation. The vessels of the electronic patient documentation, into which the pastoral care information can be fed, were then defined, so that the treatment team, in particular the nursing staff, has access to it. The results of the working group were submitted to the management of the hospital for appraisal and received approval. Since then, the pastoral care department has had partial access to the electronic patient documentation of all patients hospital-wide, passively (i.e., information can be collected) as well as actively (i.e., information can be fed in).

This access to the information system WiCare is restricted to selected modules, such as patient information, reports, and protocols as well as the Departure/ Transfer field.

Pastoral care information is fed into the system and may record, for example:

- That the patient was visited by a chaplain or is visited regularly

- That faith, religion, or spirituality is an important resource for the patient

- That the chaplain should be informed about a deterioration of the general health or about the presence of relatives

- That contacts have been established with pastoral workers of other languages, denominations, or religions

- That an anointing of the sick has taken place or is planned

As the healthcare chaplains themselves note, this information about the patients does not have a great direct influence on the content of the pastoral work, but it is helpful for pastoral organization. Access to WiCare simplifies the interprofessional flow of information and makes it more reliable. It raises the profile of pastoral care with the treatment team as the work of the pastoral care team becomes more visible. This in turn leads to greater interprofessional networking. Information flows more directly between the people involved (nurses, doctors, therapeutic services, pastoral care, etc.). Less information is lost, and stored information can be quickly viewed by all. This leads to less duplication and thus helps to ensure good patient care. "Our entries in the system make our work visible to all carers. We show that we are part of the interprofessional care team and that we can often act as a hinge between patients, relatives and caregivers." 11

\footnotetext{
${ }^{11}$ Martin Rotzler (catholic leader of the pastoral care team) and Christoph Wettstein (chaplain). This whole section about the pastoral documentation in the city hospital Triemli owes much to their information and assessments. I'm very grateful for their support.
} 


\subsection{Inselspital, University Hospital in Bern ${ }^{12}$}

The Inselspital employs around 8300 employees who look after about 44,000 inpatients and over 300,000 outpatients. The ecumenical pastoral team consists of 10 Reformed and Roman Catholic chaplains. The team positions itself as a component of holistic care and is, as such, a supportive service alongside others (e.g., social counseling, psycho-oncology, and palliative care) within the extended treatment team. The pastoral team is in contact with the nursing staff and the ethics department and participates in interdisciplinary (IDR) and interprofessional (IPR) reports. It obtains information from the nursing anamnesis and the respective screening or assessment models of the clinics - and its work can be integrated into the therapy plans (e.g., in neurology and neurorehabilitation).

\subsubsection{Interprofessional Documentation: i-pdos}

The i-pdos contains a hospital-wide IT-supported patient file to which various occupational groups have access. Medical, nursing, and therapeutic documentation have central importance. Access rights are regulated individually. The "I" in the program name means "integrated" but also "Inselspital-wide," "IT-aided," "interdisciplinary," and "interprofessional." Pastoral care in i-pdos does not document the content of conversations but only the reason for the meeting, the mode in which it was conducted, and arrangements for any future pastoral care. The pastoral entries in the i-pdos inform other professional groups about pastoral intervention and serve as a basis for in-depth, interprofessional cooperation (Fig. 7).

\subsubsection{Internal Documentation: Seel:is}

In 2012, after other pastoral and psychological assessment tools had been examined, the internal pastoral information system "Seel:is" was introduced, following an intensive development and evaluation phase within the pastoral team after intensive study of other pastoral and psychological assessment tools. The entries in the Seel:is are, in contrast to those in the i-pdos, only visible to the pastoral team members and serve the purposes of intraprofessional cooperation as well as quality assurance for individual chaplains and the pastoral team as a whole. The system essentially consists of two tools, the cockpit and the process tool: General information about a patient is recorded in the cockpit. The process tool displays the current patient dossier and is updated each time the patient visits the hospital. Information that is subject to special secrecy restrictions is entered in the "History" field. This field is only ever visible to the user who submitted the entry, regardless of who is the

\footnotetext{
${ }^{12}$ I am very grateful to Hubert Kössler and Thomas Wild, the two co-leaders of the chaplaincy team at the Inselspital, for providing me with useful information and for reviewing this chapter.
} 


\section{General situation \\ Contact offer / request of patient / of relative \\ Exceptionally stressful situation (emergency care) \\ Situation of dying}

\section{Actions}

Procedural support

Existential and/or spiritual support

Religious service

Emergency psychological intervention (emergency care)

Ethical decision support

Triage / networking

Inclusion of relatives

\section{Arrangements}

Next conversation: (weekday, date, possibly name)

Check back again (e.g. next week)

No further meetings agreed

Patient / relatives to get in contact if necessary

Fig. 7 i-pdos - Checkboxes Pastoral Care

current dossier owner. If the patient is later transferred to another pastor, the field remains hidden to this chaplain.

The objectives of Seel:is are:

- Collecting basic information: the most important information about pastoral intervention and support is collected and serves as a basis for the continuation of the support and for the personal quality assurance of the work.

- Information transfer: for the further support of a patient by another chaplain (in case of absence) and for the reconstruction of a critical incident.

- Statistical recording: the recorded data is used to record team performance and to evaluate performance according to a wide range of criteria (e.g., presence at certain clinics, involvement with certain groups of people). They thus serve as a justification of the use of funds, a basis for quality development and as material for research projects.

The Seel:is documentation tool will now be presented in more detail using an anonymous case study. Here is the information displayed in the cockpit and process tool (Figs. 8 and 9):

Significantly, following the development of the electronic patient file, the Seel:is will be integrated into the unified documentation system of the "Inselspital." 


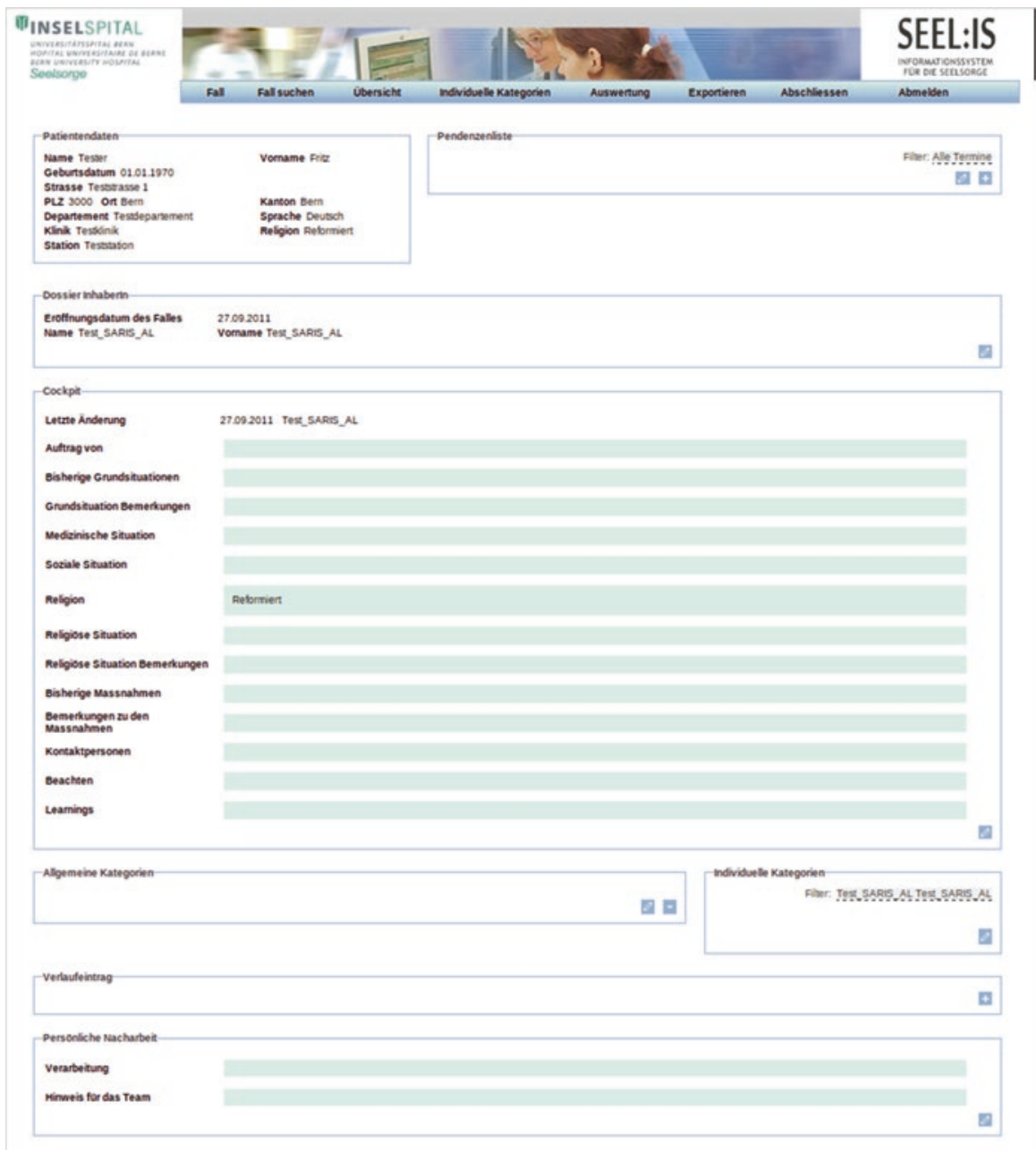

Fig. 8 Seel:is, Cockpit. (Reproduced with permission from University Hospital Inselspital Bern. Copyright (C) 2020 University Hospital Inselspital Bern. All rights reserved)

\subsection{Lausanne University Hospital ${ }^{13}$}

The "Centre Universitaire du Vaud (CHUV)" employs 11,364 people and has beds for 1568 patients. The pastoral care team comprises 18 Reformed and Catholic chaplains.

\footnotetext{
${ }^{13}$ I am very grateful to François Rouiller, team leader, and Annette Meyer, member of the chaplaincy team at the $\mathrm{CHUV}$, for providing me with useful information and for reviewing this chapter.
} 


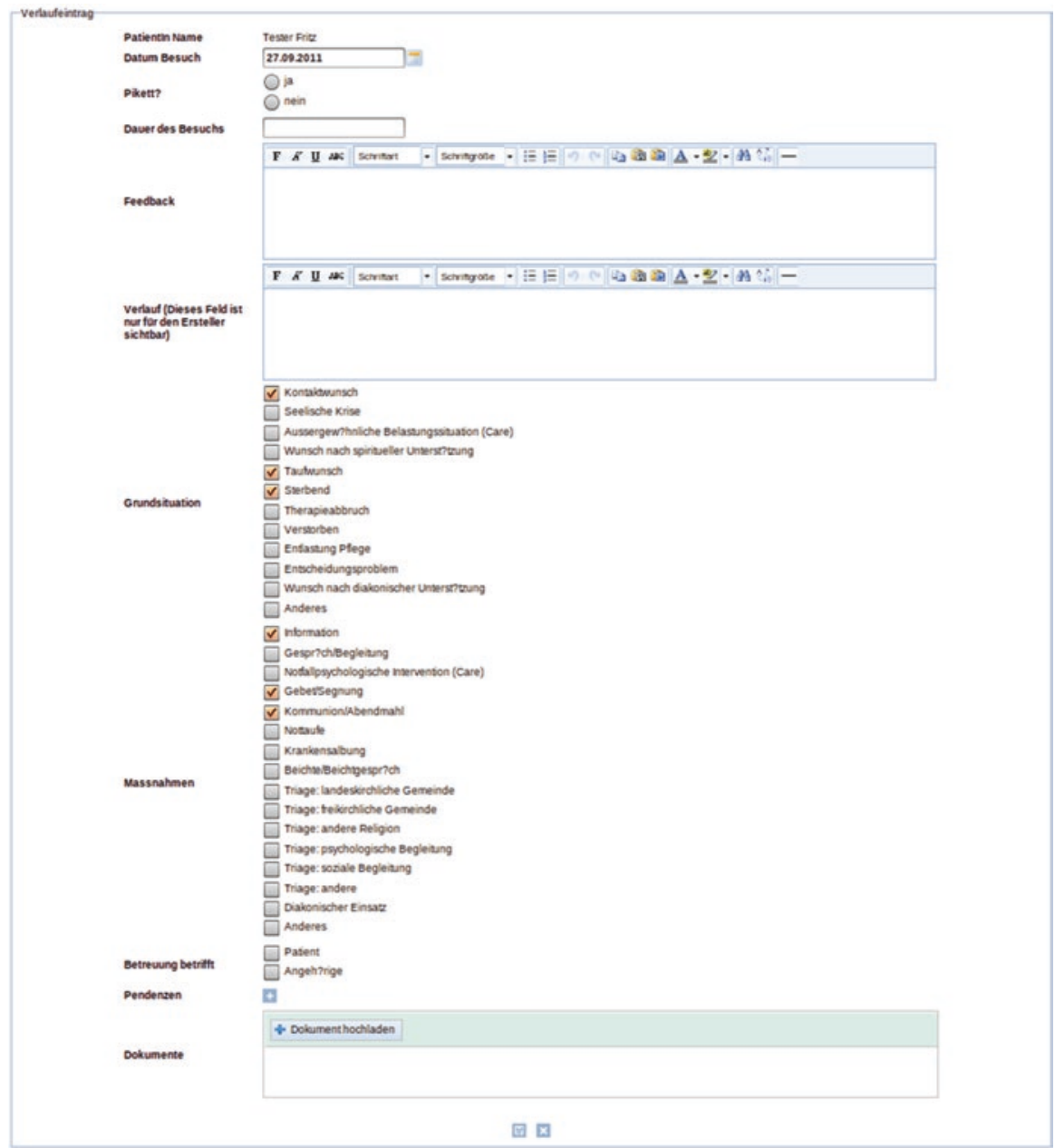

Fig. 9 Seel:is, progress entry. (Reproduced with permission from University Hospital Inselspital Bern. Copyright @ 2020 University Hospital Inselspital Bern. All rights reserved)

The electronic documentation of pastoral care was introduced in all clinics 3 years ago (2016). The basic tool is the assessment instrument STIV (French acronym for "Sense, Transcendence, Identity, and Values") and the associated SDAT (French acronym for "Spiritual Distress Assessment Tool"). The two tools are briefly presented below. 


\subsubsection{STIV and SDAT: The Conceptual Foundations of Documentation}

The STIV was developed in the field of geriatrics by the chaplain Etienne Rochat together with the physician Stéfanie Monod-Zorzi in order to support elderly, vulnerable people during their clinical stay in such way that their spiritual dimension would also be taken into account. The STIV is therefore not a general spiritual assessment tool but has its place in hospital life. In this context, the preservation of autonomy and the experience of the meaningfulness of one's own life are recognized as central spiritual needs.

Basic for the STIV is the bio-psycho-socio-spiritual health model, on the basis of which an assessment model was developed which understands the spiritual dimension as an integrative dimension of health: "The patient's spirituality is not only taken into account and evaluated in the same way as the other traditional biological, psychological and social dimensions, but also integrated into the construction of the patient care project" (Monod-Zorzi 2011, 47).

The objectives pursued are to (Monod-Zorzi 2011, 30):

- Promote the autonomy of the person

- Mobilize spiritual resources to better integrate the disease or crisis

- Better understand patient expectations and treatment choices

The STIV model of spiritual needs provides a structured and systematic approach to the appraisal of patients' spirituality. This approach, based on the assessment of patients' spiritual needs, is consistent with the care approaches of medicine and nursing and is therefore understandable to caregivers (Monod-Zorzi 2011, 65). It is assumed that the chaplain is a full member of the treatment team. The interdisciplinary conference stage is therefore crucial, because it represents the real moment of integration of this spiritual dimension with the other traditional bio-psycho and social dimensions (Monod-Zorzi 2011, 59).

Rochat and Monod characterize the spiritual dimension of sick, hospitalized people in the following categories (Monod-Zorzi 2011, 51f):

- Meaning. This concerns the need for a global balance in life, the need to live with a disease or to integrate limitation and disability into life.

- Transcendence. This is about the need for connectedness, which can be expressed in different forms - religious or non-religious.

- Values. This is about a person's value orientation, which comes into play in his or her life decisions. In the hospital, it is a question of these values being recognized and the possibility of maintaining control being maintained (e.g., through involvement in the decisions of the treatment team).

- The psychosocial aspects of identity. This is about the need to maintain one's (unique) identity. 
On the basis of the STIV, Monod and Rochat developed a tool for measuring spiritual distress called SDAT for Spiritual Assessment Tool. This tool helps to identify unmet spiritual needs and determine their severity. Spiritual stress is determined with reference to the four categories of the STIV and recorded using a scale from 0 (spiritual needs are not fulfilled at all) to 3 (spiritual needs are fulfilled).

\subsubsection{The Documentation Tool}

Documentation is provided on two pages: one can only be viewed by the members of the pastoral team, while the other is also accessible to the interprofessional team.

The pastoral page collects general information about the patient (dossier aumônerie), records any interventions, and contains the patient's spiritual anamnesis, which is created using the STIV and is the basis for the spiritual evaluation:

Evaluation STIV:

- Meaning (observations - hypotheses)

- Transcendence (observations - hypotheses)

- Values V1 ${ }^{14}$ (observations - assumptions)

- Values V2 (observations - assumptions)

- Psycho-social aspects - Identity (observations - hypotheses)

The spiritual evaluation is accessible to the interprofessional team. The evaluation always refers to the current situation and is not a static value. It is determined by assessing which spiritual needs are currently in the foreground for the patient through the evaluation of the four categories. In addition to the spiritual evaluation, the interprofessional page records any recommendations for the treatment team and provides space for further observations and information.

Chaplaincy Point:

- Results of spiritual evaluation (STIV/SDAT)

- Recommendations

- Notes and observations

Efforts are already underway to develop the documentation tool further: The pastoral team is, on the basis of the STIV, currently developing another tool to be complementary to SDAT: the STIV-RePer, which will assess patients' worries (French: PERturbations) and the spiritual resources available to them. The pastoral care team is also currently revising the documentation tool itself, with the aim of (a) reducing time expenditure, (b) giving more weight to spiritual resources, and (c) reducing the room for interpretation.

\footnotetext{
${ }^{14}$ Valeurs 1 are the values that are important for the patient in general. Valeurs 2 are those values that are particularly relevant for the current hospital stay.
} 


\subsection{Goals and Current Practice: Charting Systems in Switzerland}

In an essay with the programmatic title "Leaving Footprints" (Ruff 1996, 390f), Rob A. Ruff formulated for the first time the central objectives of pastoral documentation:

- Chaplains are integral members of the interdisciplinary care team.

- Documentation will help create more visibility for the chaplain as a professional.

- Documentation of spiritual interventions is proof of compliance with regulatory requirements by the Joint Commission to provide for the spiritual needs of all patients.

Since pastoral care can leave its footprints in the hospital's documentation in all three hospitals presented above, it seems that the objective of integrating chaplains into to interdisciplinary team is being pursued and has been at least partially achieved.

Comparison of the three documentation systems shows that the development of interprofessional cooperation has reached different stages in different hospitals.

The development in the Triemlispital in Zurich shows how the hospital has already made it far from self-evident that it is possible for pastoral care to have access to patient documentation. This is probably because pastoral care is not regarded as an integral member of the interprofessional team. Only when the pastoral care team was able to show how the insufficient exchange of information in patient care could actually lead to disabilities and difficulties the hospital management gave permission to the pastoral care team to read and to feed at least some of the information of their pastoral support. Pastoral care is thus enabled to leave footprints by documenting their encounters and recording whether faith, religion, or spirituality is a relevant resource for the patient. However, there is no detailed information about the concrete needs of the patient or the specific interventions of the pastoral care team.

The pastoral care team at the Inselspital in Bern has long been an undisputed interprofessional partner in most clinics and thus an integral part of many treatment teams. Consequently, the pastoral counseling department has access to electronic patient documentation in all clinics and can also make entries. It provides information about the patient's situation, about what led to the consultation (contact offer or request, crisis, death situation) and about any pastoral care activities (procedural support, crisis support, ethical support, etc.). In addition, the documentation informs the treatment team about future pastoral care support.

The footprints of pastoral care work are visible in the system and give an approximate idea of the nature of the intervention through the specification of pastoral activities. A special strength of the pastoral documentation of the Inselspital - also when compared to hospitals worldwide - lies in the fact that it generates very 
precise statistical data and can provide detailed information on a wide variety of interrelationships.

Interprofessional collaboration seems to be most advanced in some CHUV clinics in Lausanne. Indeed, the assessment instrument STIV, which is the basis for the clinics' documentation, was developed in interprofessional collaboration. This development took place against the background of long-standing efforts by pastoral care to understand and represent the spiritual dimension as part of health care. These efforts have been supported by cantonal legislation, which makes provisions for the spiritual dimension. In the pastoral care documentation, which the entire treatment team can view, the result of the spiritual evaluation is recorded, and recommendations for the treatment team are formulated.

For this form of documentation, the image of footprints is no longer appropriate. Here, pastoral care does not merely leave traces but intends to participate fully in the healthcare of patients with its own expertise. Its contribution is integrated into the work of the care team, and its assessments are considered by the other health professionals and influence their actions.

Although the documentation systems in the Inselspital and, perhaps most clearly, in the CHUV suggest that pastoral care has now been integrated into interprofessional care, some critical remarks are necessary. The existence of an interprofessional documentation tool does not necessarily mean that interprofessional work is actually carried out. "Paper is patient," they say, and electronic dossiers can just be as patient. Firstly, there is the question of who actually reads the documented pastoral contributions. Secondly, the question arises as to the consequences of interprofessional cooperation and, ultimately, of care support. Are there tools for quality assurance? How does using a documentation tool affect the work of health professionals? Are they properly trained in such a way that they can include the spiritual dimension in their actions? These and other questions will have to be addressed in further research projects if we are to understand the true relevance of pastoral documentation.

\section{Summary and Future Perspectives}

The survey and the discussions with Swiss chaplains about documentation reveal three things:

- First, there is a great interest in the topic among Swiss chaplains.

- Second, there is an open or positive attitude toward documentation, with many chaplains already documenting, be it for the purposes of interprofessional cooperation, or for the purposes of cooperation within palliative care, and the majority 
of chaplains are open to documentation as part of interprofessional collaboration.

- Third, there are worries about how the pastoral secret is affected, whether documentation changes the profile of pastoral care in an unacceptable way (e.g., to medicalize it), and whether it is appropriate to communicate pastoral information in written form, given the possibility of security breaches.

Many of the factors that have promoted the development of documentation arose first in the field of palliative care: the fact that interprofessional cooperation, in which pastoral care is integrated, is usually standard in (specialized) palliative care, the requirements of palliative complex treatment as part of financing, and the documentation standards developed by the Pastoral Care Section of palliative.ch. This results in requirements such as joint documentation.

Other factors that promote documentation have to do with the general task and cooperation of pastoral care with other professions in the hospital. Where pastoral care takes over the function of a hospital's internal care team, documentation is important for transfer of cases as well as for the purpose of assessing the quality of the service for the institution: Plausibility check of the service vis-à-vis the institution, the understanding of pastoral care as part of the interprofessional team and thus the standard of interprofessional cooperation as it is increasingly applied in larger hospitals in Switzerland and the need for statistical data to demonstrate the need for pastoral care on the part of the funding institution.

Some factors that hinder the development of pastoral documentation or question its necessity come from within the field of pastoral care and from the church. There is no consensus within the field of pastoral care because there are hardly any developed theories of pastoral documentation, with the consequence that documenting plays no part in pastoral education and training. Meanwhile the position of the churches with regard to documentation varies from canton to canton and from confession to confession.

Other hindering factors come from outside: the legal situation is unclear or controversial, and the political situation varies depending on the canton.

So, looking to the future, what should be done? First of all, and most fundamentally, it must be clarified how interprofessional cooperation can or should be structured and whether, or in what form, the documentation is a helpful contribution to this. Beyond that, clarification of the ethical and legal requirements is needed in order to define the possible scope of documentation and provide a clear ethical and legal framework for dealing with the secrecy of pastoral care.

Regardless of how one approaches pastoral documentation, the questions it raises lead to highly exciting and relevant discussions about the future shape of pastoral care in the institutional environment and beyond. 


\title{
Commentary
}

\author{
Wim Smeets $(\bowtie)$ \\ Radboud University Medical Center, Nijmegen, The Netherlands \\ e-mail:Wim.Smeets@ radboudumc.nl
}

There are similarities and differences between the way charting has evolved in Switzerland as reflected in Pascal Mösli's fascinating contribution - and its development in other countries. The challenges for charting in Switzerland are distinctive in some respects, but have much in common with those faced elsewhere.

\section{Similarities}

First I will mention the similarities. I see five of them. First of all, charting is developing rapidly in Switzerland, just like in other countries. Until recently only a few hobbyists were interested in an well-structured, shared written documentation of patient contact. Today the entire professional group is dealing with the theme. Second, this recent development is not due to a spontaneous awakening of professional awareness, but is driven by external factors. Just like in the Netherlands, for example, the emergence of integrated palliative care is one of the most important reasons. Palliative teams expect pastors to carefully and richly document their findings and actions, just like other professions do; otherwise the spiritual dimension cannot be properly integrated into healthcare. In our country, the Netherlands, this has even led to the development of a new professional position, the spiritual care consultant: he or she can fully participate in the team - and therefore also report - without being hindered by discussions about professional secrecy. The work of the Taskforce Spiritual Care of Palliative.ch and the influence of the "Pastoral Care as Specialized Spiritual Care in Palliative Care" guidelines can be compared with a similar Task Force and the revised guideline "Meaning and Spirituality in Palliative Care" in the Netherlands. It is expected that the application of such guidelines will stimulate the further development of charting. Third, the professional group of (German-speaking) pastors is very divided about whether or not to participate in the interdisciplinary registration of patient contacts. The same division can be seen in other countries; the debate is perhaps equally emotional everywhere. It slows the development of charting and makes it difficult to speak with one voice to companies that develop electronic documentation systems. In this way a mix of systems and documentation methods remains. Fourth, training is an important incentive to discuss data about patient contacts with others. Clinical Pastoral Education has also played a key role in other countries for many years, stimulated by the legacies of Boisen, Gerkin, and other inspirational figures who advocated for learning through living human documents. Fifth, there is the central role of the professional association. It is only since these associations have come to realize the importance of charting that we have seen the development from separate, in themselves valuable, initiatives toward a joint approach.

\section{Differences}

Then there are the differences. I will mention three of them. In Switzerland, the arrival of a national electronic patient file (the law of April 2017) might be an important stimulator for pastoral documentation, or should we say that the law leaves pastors no choice? In the Netherlands, the parliament has blocked similar initiatives for a national electronic patient file with an appeal to the privacy of the citizen. This aversion to government interference in private life is perhaps something typically Dutch - due to negative experiences during the Second World War - a sentiment that may be difficult to understand for outsiders. A second difference is the influence of emergency care on the development of documentation sys- 
tems. It would be interesting to hear in more detail how emergency care in Switzerland promoted the professionalization of pastoral care; in the Netherlands we are still at the beginning (Pater, R., W. Smeets, and A. de Vries. 2019. A beacon in a storm: Competencies of healthcare chaplains at the Accident \& Emergency Department. Journal of Healthcare Chaplaincy [in press]). The biggest difference, however, lies in conducting a national survey among pastors. Although opinions have also been canvassed in other countries, the recent national survey in Switzerland offers a very complete picture of pastors' opinions about charting. The significance of these empirical data, also for the international discussion, cannot be sufficiently stressed. This research is therefore of significant merit! It makes clear, among other things, what a difference it makes whether pastors are employed by institutions or are employed by the church (with variation by canton and by denomination). The largest group of pastors who chart do so on behalf of their institution and with a view to interprofessional cooperation.

\section{Challenges}

Partly based on the three cases presented by Mösli, five challenges can be formulated, which the Swiss situation shares with those in other countries. The diversity in design of the three examples firstly points to the need for greater uniformity in the reports. The practice of charting often develops pragmatically through the initiative of a few pastors. This approach has the advantage that these "footprints" are closely aligned with what is required for action. The disadvantage is that models depend on personal insights and beliefs and therefore they have a limited scope, as Mösli states: sometimes rather process-oriented, sometimes rather result-oriented, but rarely linked to quality standards, in order that the content of the work would also benefit from reporting. Second, it is desirable that the developed models have a scientific basis. The Lausanne model is a unique example in that regard, because it is based on the Spiritual Needs Model of Stéfanie Monod. This model is related to the Spiritual Needs Model of Fitchett, which we have taken as a starting point in Nijmegen and elsewhere in the Netherlands. With this scientific basis, the randomness of some lists can be avoided. It offers other professionals insight into the scope of pastors' work. Pastoral care is integrated into a holistic view of health. Ruff had arrived at that insight more than 20 years ago, Mösli rightly observes. Third, reporting in this way can be an important building block of research on the profession of pastors and spiritual caregivers. At the moment we are still very dependent on general sociological studies on the religious or spiritual status of the population of a country. With scientifically based reporting systems we can gain a deeper insight into the religious and spiritual attitudes of specific population groups, into the interventions that pastors undertake and the effects thereof. This type of data goes much further than the outcome studies that are currently being set up. Fourth, a full report also provides starting points for aftercare outside the institutions. Aftercare is not possible without a proper report. That is why the Netherlands is now also considering reporting activities by spiritual caregivers and pastors in the home context. This challenge was recognized many years ago by the international Rehabilitation Movement in psychiatry. This makes the documentation by pastors of their actions from the perspective of empowerment indispensable. At the end, Mösli lists what is needed for the further development of reporting. All the elements mentioned are important. What I miss - and this is the fifth and final challenge - is the further development of reporting by and through education and training. Collaboration by pastors among themselves and between pastors and other disciplines would benefit if best practice and critical experiences were shared, or if there were some form of joint supervision. This requires a thorough substantive report on the practical case studies. Working together this way would also encourage each participant in the training to deepen their own reporting. Guidelines only work when training increases knowledge, when skills are practiced and desired attitudes are developed.

The international sharing of reporting insights and practices will improve the quality of reporting systems. The examples presented here, especially the detailed descriptions from 
Bern and Lausanne, can provide inspiration for working groups of professional associations to lay alongside their own models. In that sense, the initiative of the Swiss to organize an international meeting of experts and to publish their findings is to be commended. It is now the responsibility of other countries to take up the initiative!

\section{References}

Famos, Rita, Matthias Felder, Felix Frey, Matthias Hügli, and Thomas Wild. 2016. Dem Anvertrauten Sorge tragen - Das Berufsgeheimnis in der Seelsorge. Bern: SEK/FEPS.

Leitlinien. Seelsorge als spezialisierte Spiritual Care in Palliative Care. 2019. www.palliative.ch/ de/fachbereich/fachgruppen/fachgruppe-seelsorge.

Lichter, David. 2015. How do we measure quality in charting? National Association of Catholic Chaplains. Vision 2015 (25/4): 3-5.

Monod-Zorzi, Stéfanie. 2011. Soins aux personnes âgées. Intégrer la spiritualité? Bruxelles: Lumen Vitae.

Ruff, Robert A. 1996. Leaving Footprints: The practice and benefits of hospital chaplains documenting pastoral care activities in patient's medical records. Journal of Pastoral Care 50: 390f.

Spiritual Care in Palliative Care. Leitlinien zur interprofessionellen Praxis. 2018. www.palliative. $\mathrm{ch} / \mathrm{de} /$ fachbereich/task-forces/spiritual-care.

Open Access This chapter is licensed under the terms of the Creative Commons Attribution 4.0 International License (http://creativecommons.org/licenses/by/4.0/), which permits use, sharing, adaptation, distribution and reproduction in any medium or format, as long as you give appropriate credit to the original author(s) and the source, provide a link to the Creative Commons license and indicate if changes were made.

The images or other third party material in this chapter are included in the chapter's Creative Commons license, unless indicated otherwise in a credit line to the material. If material is not included in the chapter's Creative Commons license and your intended use is not permitted by statutory regulation or exceeds the permitted use, you will need to obtain permission directly from the copyright holder.

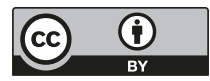

